\title{
Modelling, Forecasting and Testing Decisions for Seasonal Time Series in Tourism
}

\author{
Cvetko Andreeski ${ }^{1}$, Daniela Mechkaroska ${ }^{2}$ \\ Faculty of Tourism and Hospitality - Ohrid, University „St. Kliment Ohridski“ - \\ Bitola, 7000 Bitola $^{1}$ \\ Faculty of Computer Science and Engineering, Skopje, Ss. Cyril and Methodius \\ University, 1000 Skopje, Macedonia ${ }^{2}$ \\ cvetko.andreeski@uklo.edu.mk ${ }^{1}$, daniela.mechkaroska@ finki.ukim.mk ${ }^{2}$
}

\begin{abstract}
Time series analysis for basic tourism parameters, in the countries of the Balkan Peninsula, have been emphasized in recent research. Moreover, some of them have also shown a trend, aside from the rising variance during the period-heteroscedasticity. All of these characteristics of a time series of tourist demand, result in them being a great challenge for modeling. Therefore, there are different types of models that can be implemented for the modeling of a time series, which include accentuated seasonal components. Throughout this paper, multiple tests are performed using several parameters of the time series, with the ARIMA model, in an attempt to find any influence on the fit and validity of the model. For the accepted models, series are predicted for a year in advance and, in addition, a method of testing the decisions made by authorities in the field of tourism is presented.
\end{abstract}

Keywords: time series; modelling; parameters; forecasting; testing; decisions

\section{Introduction}

The modeling and forecasting of a time series plays a vital role in the process of planning and decision making in the tourism industry, which accounts for the vast number of papers on these issues. In the paper [15], modeling and forecasting is made for basic tourism parameters, from 1953-2014, sampled as annual data. This series is a challenge for modeling, as it contains two structural breaks. For the modeling, a standard ARIMA model is implemented according to what can be found in [2]. Alternatively, in paper [20], the authors used several competing models, mainly based on models for time series analysis and commenting on the results of modeling and forecasting of a series of arrivals in Australia. On the other hand, in paper [1] and [6] the main aim of research is the comparison between linear ARIMA models and non-linear models based on artificial neural networks. In paper [1] we can find an exploration of their performances for modeling time 
series with existing break(s). Nevertheless, many authors have worked on time series modeling with seasonal components by using neural networks [3] [6] [13] [19], as time series with a significant seasonal component are important in different areas of research like economy [7], climate forecast [17], biology [18], medicine [8], etc. Aside from their performances in modeling, especially in modeling time series with occurring structural break(s), these models are much more complex than linear models. They have the potential problem of getting values of weights from the local minimum, so the results of forecasting can be disappointing, or fail to meet previous expectations based on the results of modeling [6] [3]. In this paper, we have analyzed time series of arrived domestic and foreign tourists with monthly data from two landlocked countries on the Balkan Peninsula: The Republic of Macedonia and the Republic of Serbia for a period of nine years. Whilst all the analyzed series have accentuated seasonal behavior, an upward trend is present, as well. All those characteristics of the series present a significant challenge for successful modeling and forecasting. ARIMA models will be used in the process of modeling and accordingly, different parameters of them will be tested to choose the best one. Correspondingly, the final chosen model will be tested for validity and forecast performance. Additionally, a forecast of future values of arrived tourists for the current year has been created. This paper presents a way of testing the decisions made in both countries aimed at supporting the growth of tourism. A few of them will be tested in different intervals for the impact that they have on the progress of tourism via increment on number of arrived tourists.

\section{Analysis of Time Series}

For the modeling, two different time series are used for each country: one concerns the domestic tourists visiting the Republic of Macedonia for the period from 01:2010 until 08:2017, and the other a series of arrived foreign tourists during the same interval. Despite the similarities of the two, we can detect different characteristics and behavior of the series. Both series have been presented for the analyzed time increment, in the Republic of Macedonia in Figure 1. From the graphical representation of the time series, several features may be noticed.

For the series of arrived domestic tourists we can conclude the following:

- The series has an accentuated seasonal component, much more heightened than is the case for the series of arrived foreign tourists at the same time.

- This series does not have a trend, although there is variation around an average value. It can be visible if we present data on an annual level.

- It has weak heteroscedasticity that should be tested. 
For the series of arrived foreign tourists from the graphical representation, we can conclude that:

- It has an accentuated seasonal component.

- Furthermore, it has a heightened upward trend at the time.

- Likewise, it also has prominent heteroscedasticity, which implies the necessity of logarithmic transformation on the original time series in order to remove the influence of the heteroscedasticity. In addition, the last analyzed year significantly differs from the behavior of the rest of the series, which warrants further testing for hypothetical structural changes.

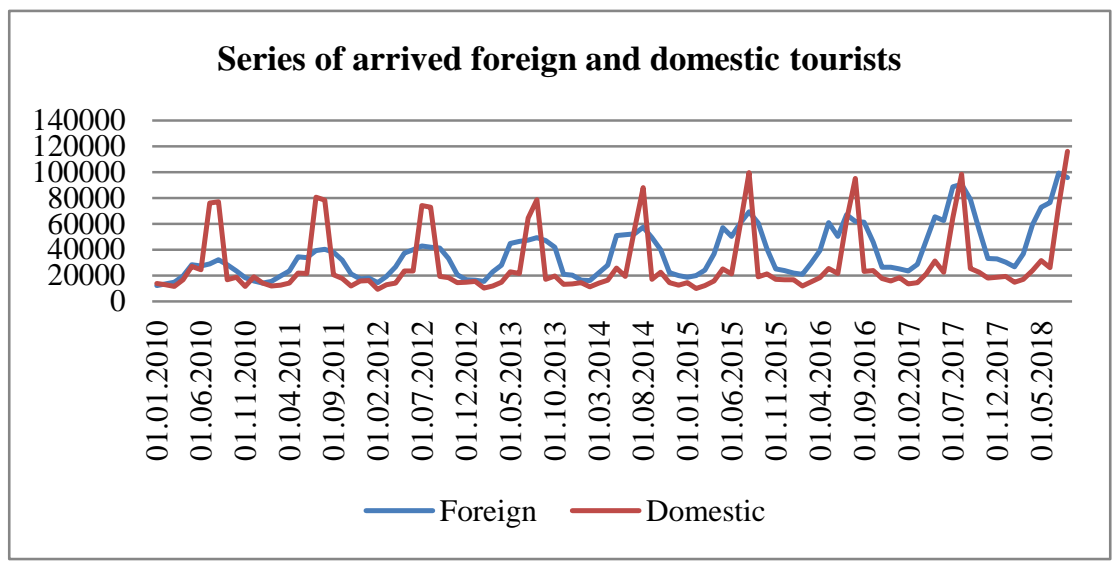

Figure 1

Graphical representation on series of arrived domestic and foreign tourists in the period 01:2010 8:2018. Source: State institute for statistics - Republic of Macedonia

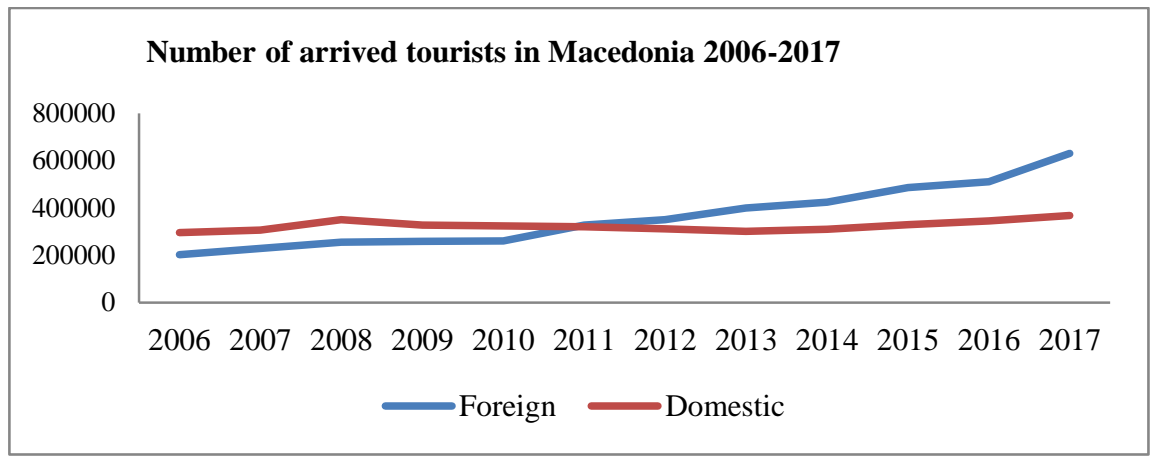

Figure 2

Number of arrived domestic and foreign tourists in the Republic of Macedonia, annual data. Source, State institute for statistics of the Republic of Macedonia 
Series with annual data of arrived domestic and foreign tourists from 2006 to 2017 are shown in Figure 2. Similarly, the upward trend of the number of foreign tourists for the analyzed period can correspondingly be noticed in Figure 2, as well as, the variation of the number of arrived domestic tourists in the same timeframe. Leading up to 2011, the number of arrived foreign tourists was lower than the arrived domestic tourists, whereas their number significantly increased for the last six years, which leads to a $71 \%$ increase in the number of visiting domestic tourists in 2017. From the period of visa liberalization for Schengen countries in 2009 until 2013, the number of arrived domestic tourists decreases, and at the last four years, it encounters a slight increment. To conclude, in the series of arrived foreign tourists, an upward trend is present between 2006 and 2017.

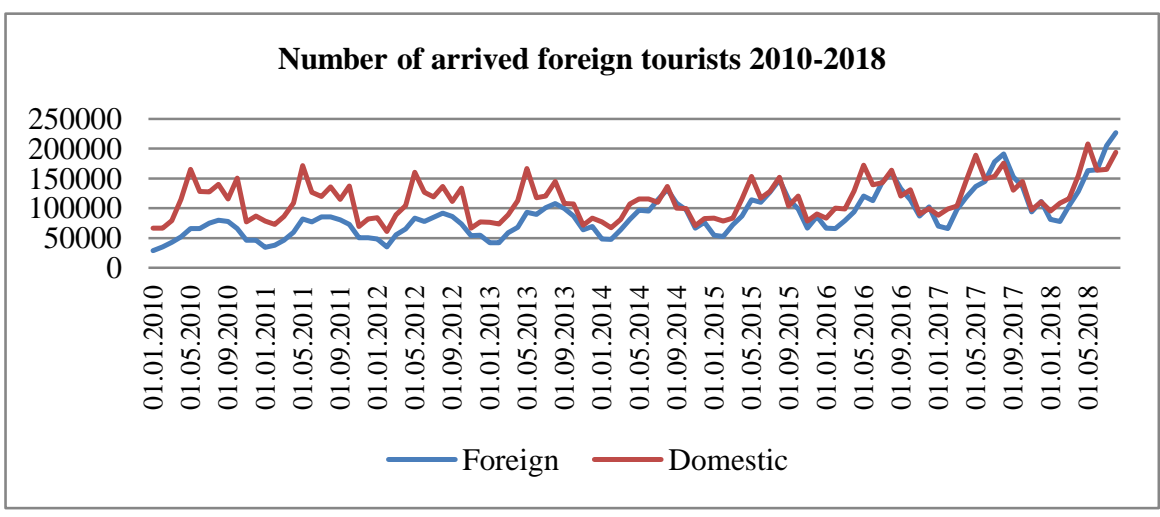

Figure 3

Graphical representation on series of arrived domestic and foreign tourists in the period 01:2010 8:2018. Source: State institute for statistics - Republic of Serbia

For the series of arrived domestic tourists in Serbia we can conclude that:

- The Series has a heightened seasonal component

- This series does not have a trend, but variation around an average value

- We should test for potential heteroscedasticity

- It changes its behavior (shape) in this phase of the analyzed time series

The series of arrived foreign tourists in Serbia suggests that:

- An accentuated seasonal component with a different pattern can be noted

- A prominent upward trend during the years is visible

- The presence of heteroscedasticity indicates the necessity of a logarithmic transformation of the original series in order to decrease that influence. 
Each series should be tested for possible structural breaks ${ }^{1}$.

Figure 4 portrays the series with annual data of arrived domestic and foreign tourists between 2010 and 2017 - Republic of Serbia, from which the upward trend of the number of foreign tourists can be observed.

On the other hand, the number of arrived domestic tourists does not show a specific trend, as it has variations around the average number of arrived tourists. Beside the fact that the series of arrived foreign tourists has a constant upward trend, the number of domestic tourists is greater than the number of arrived foreign tourists.

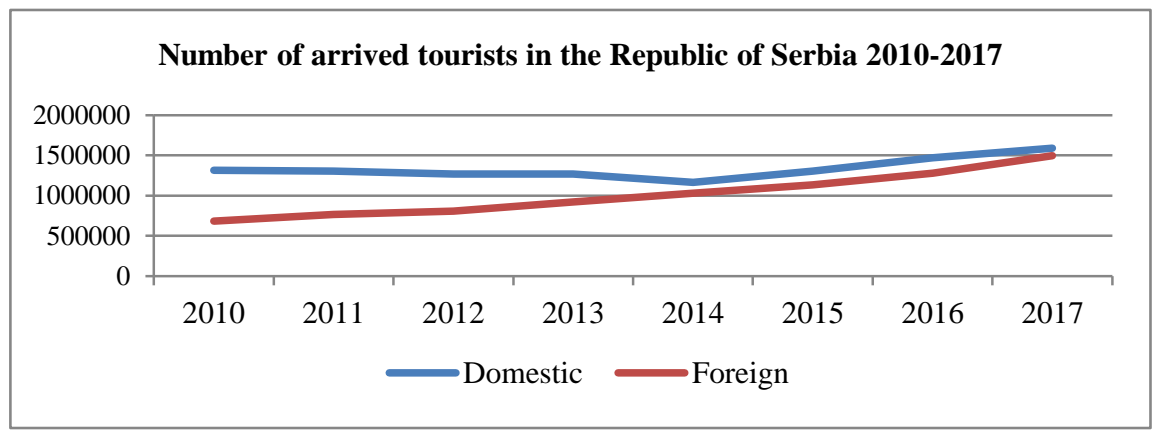

Figure 4

Number of arrived domestic and foreign tourists in the Republic of Serbia, annual data. Source, State institute for statistics of the Republic of Serbia

\section{Modeling of Time Series}

Autoregressive moving average model (ARMA) for stationary time series is a linear structure of two polynomials, one for the auto-regression (AR) and the second for the moving average (MA).

A stationary $\operatorname{ARMA}(p, q)$ model is defined as a linear sequence of autoregressive random variables $X_{t}$, and moving average random variables $Y_{t}$ with zero mean value and constant variance provided by (1):

$X_{t}-\varphi_{t} X_{t-1}-\ldots-\varphi_{p} X_{t-p}=Y_{t}+\theta_{1} Y_{t-1}+\ldots+\theta_{q} Y_{t-q}$

If the time series is non-stationary, we need to differentiate the series in order to get a stationary one. In this case we have an $\operatorname{ARIMA}(p, d, q)$ process where $d$ is a

1 Structural break is an abruptly change of time series at a point in time. This variation could involve a change in mean or a change in the other parameters of the process that produce(s) the series. 
non-negative integer such that $(1-B)^{d} X_{t}$ is a causal ARMA(p,q) process [5]. All the analyzed time series in this paper are sampled by monthly data.

A series of arrived domestic tourists in the Republic of Macedonia will be the first analyzed time series, which has a seasonal component, without a trend. We have made one differencing of the series and we have tested the resulting series in order to conclude if it is stationary, as this is necessary for modelling. Augmented Dickey Fuller test was performed to check the status of the series and the results can be observed in Table 1.

Table 1

Unit root test for number of domestic tourists in the Republic of Macedonia

Null Hypothesis: D_DOMESTIC has a unit root, Exogenous: Constant

Lag Length: 10 (Automatic - based on SIC, maxlag=12)

\begin{tabular}{lccc}
\hline & & t-Statistic & Prob.* \\
\hline Augmented Dickey-Fuller test statistic & -59.39975 & 0.0001 \\
\hline Test critical values: & 1\% level & -3.503049 & \\
& 5\% level & -2.893230 & \\
$10 \%$ level & -2.583740 & \\
\hline
\end{tabular}

The critical values are much higher than the test statistics and the probability of rejection on null hypothesis is close to 0 as table one suggests, which indicates that the differenced time series is stationary.

At the beginning of the modeling, a Correlogram should be consulted for the lags of the series in order to detect the most significant parameters. The values of the autocorrelation of the lags and the partial autocorrelation are stated in Figure 5.

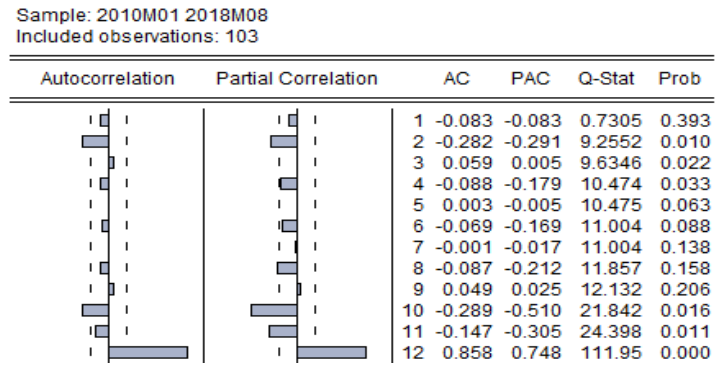

Figure 5

Autocorrelation and partial autocorrelation values of the lags of series

From the values of the Correlogram, we can conclude that the 12 lag has a significant value of correlation, furthermore, the variation of the values can be deduced from the partial autocorrelation values, or potential serial correlation of the lags. ARIMA(1,1,1) model can be proposed, the results are reported in Table 2 . 
From the results gathered from Table 2, we can conclude that:

- $\quad$ The probability that chosen variables will be rejected is low

- The fit of the model is good, so we can expect to have a suitable forecast

- According to Durbin-Watson statistics, the result is not conclusive, so we need to test the residuals in order to identify if they are uncorrelated.

Table 2

Model of series AR(12), MA(1)

Dependent Variable: D_DOMESTIC

Method: ARMA Maximum Likelihood (OPG - BHHH)

Date: 12/09/18 Time: 13:47, Sample: 2010M02 2018M08

Included observations: 103, Convergence achieved after 14 iterations

Coefficient covariance computed using outer product of gradients

\begin{tabular}{|c|c|c|c|c|}
\hline Variable & Coefficient & Std. Error & t-Statistic & Prob. \\
\hline $\mathrm{AR}(12)$ & 0.990949 & 0.003742 & 264.8407 & 0.0000 \\
\hline $\operatorname{MA}(1)$ & -0.922846 & 0.051716 & -17.84435 & 0.0000 \\
\hline SIGMASQ & 12678529 & 1188167. & 10.67066 & 0.0000 \\
\hline R-squared & 0.979357 & \multicolumn{2}{|c|}{ Mean dependent var } & 994.7282 \\
\hline Adjusted R-squared & 0.978944 & \multicolumn{2}{|c|}{ S.D. dependent var } & 24903.88 \\
\hline S.E. of regression & 3613.708 & \multicolumn{2}{|c|}{ Akaike info criterion } & 19.72877 \\
\hline Sum squared residuals & $1.31 \mathrm{E}+09$ & \multirow{2}{*}{\multicolumn{2}{|c|}{$\begin{array}{l}\text { Schwarz criterion } \\
\text { Hannan-Quinn criter. }\end{array}$}} & 19.80551 \\
\hline Log likelihood & -1013.032 & & & 19.75985 \\
\hline Durbin-Watson stat & 1.579279 & & & \\
\hline
\end{tabular}

In Figure 6, we can see the Correlogram of the residuals. From it, we can conclude that the residuals are uncorrelated, and they are inside the range of $\pm 2 \mathrm{SE}$.

Included observations: 103

Q-statistic probabilities adjusted for 2 ARMA terms

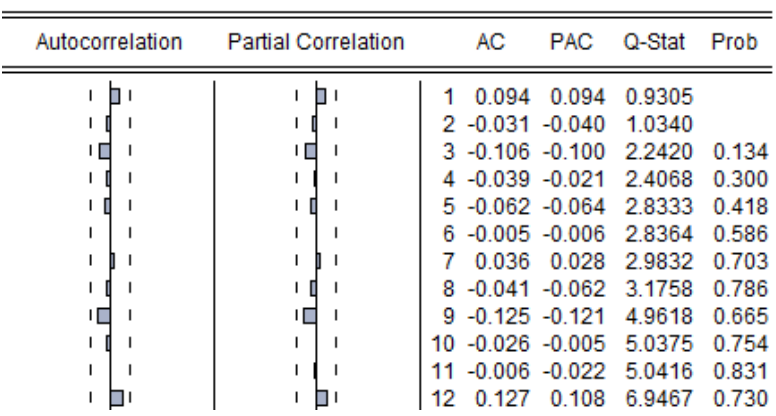

Figure 6

Correlation analysis on residuals of the model 
The results provided in Table 3 imply that there is no heteroscedasticity of the residuals, and the model is valid. Hence, the residuals are uncorrelated and there is no heteroscedasticity in this series. This model grants us an opportunity to forecast future values of the series, aside from covering almost $98 \%$ of the variance of differenced series.

Table 3

Heteroscedasticity White Test on residuals

Heteroskedasticity Test: White

\begin{tabular}{lll}
\hline F-statistic & 172.8046 Prob. F(6,96) & 0.0000 \\
Obs*R-squared & 94.27140 Prob. Chi-Square(6) & 0.0000 \\
Scaled explained SS & 305.8439 Prob. Chi-Square(6) & 0.0000 \\
\hline
\end{tabular}

Figure 7 portrays an in sample forecast of the values 01-08.2018.

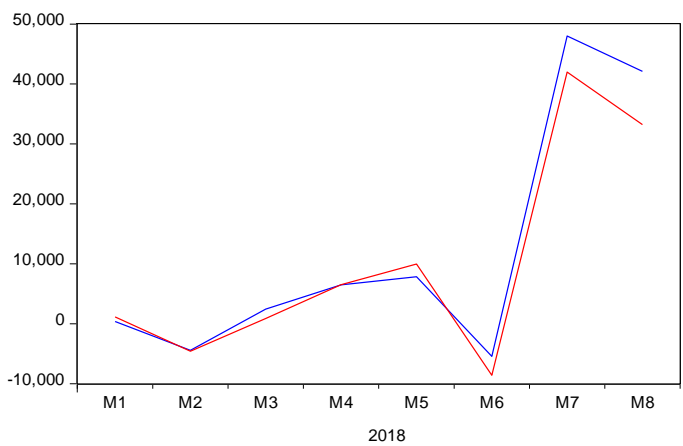

--- D_DOMESTIC

---D_DOMESTICF

Figure 7

In sample forecasting of the series for 2018

Figure 8 represents the forecast of values for the analyzed series of arrived domestic tourists in 2019, and illustrates a comparison of the values with the previous year.

From there, we can deduct that the series of arrived domestic tourists in 2018 and the predicted values for 2019 are almost identical. The difference within the entire predicted timeframe is minor, but taking into consideration the fact that a trend was not present in the series, this result is to be expected.

The second modeled series, is the series of arrived foreign tourists in the Republic of Macedonia in the period between 01.2010 and 08.2018. This series is more complex for identification, taking into consideration the fact that this series has a trend, seasonal component, and evident heteroscedasticity. As can be seen by these characteristics of the series, a logarithmic transformation on the original series has been conducted, as well as differencing the series in order to create a stationary one. 


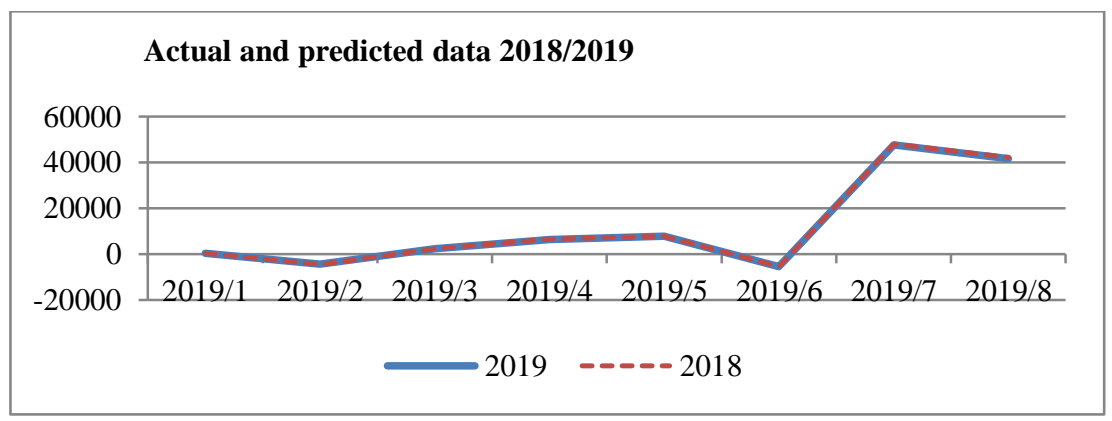

Figure 8

Graphical presentation of original series 01-08.2018 and predicted data 01-08.2019

Prior to modeling, a unit root test was performed on the transformed series in order to test whether the series is stationary. The results of the aforementioned testing are conveyed through Table 4.

Table 4

Unit root test results for the series of foreign tourists in the Republic of Macedonia

Null Hypothesis: LOG_FOREIGN_D has a unit root Exogenous: Constant

Lag Length: 11 (Automatic - based on SIC, maxlag=11)

\begin{tabular}{lccc}
\hline \hline & t-Statistic & Prob.* \\
Augmented Dickey-Fuller test statistic & -4.945204 & 0.0001 \\
\hline Test critical values: & $1 \%$ level & -3.511262 & \\
$5 \%$ level & -2.896779 & \\
$10 \%$ level & -2.585626 & \\
\hline \hline
\end{tabular}

The test results indicate that one differencing of the series is enough to create stationary series. Hence, the modeling of the series should be commenced. A matrix of autocorrelation and partial autocorrelation values of the series lags were performed as is depicted in Figure 9.

The results of the Correlogram indicate (autocorrelation-AC and partial autocorrelation-PAC) patterns of serial correlation of the lags in both columns. Consequently, in the model of the series by itself, two parameters can be found. While the first one MA(1) is engaged for modeling serial correlation, the $12^{\text {th }}$ lag explains the seasonality of the series. Correspondingly, it is to be expected that these two lags will be very significant for this model.

During the phase of testing different models for validity, we have checked whether the series itself has different behaviors in different periods. 


\begin{tabular}{|c|c|c|c|c|c|c|c|c|}
\hline Autocorr & relation & Partial Co & orrelation & & $A C$ & PAC & Q-Stat & Prob \\
\hline 15 & $\square$ & 15 & $\square$ & 1 & 0.438 & 0.438 & 18.806 & 0.000 \\
\hline 1 & 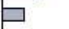 & 1 & 1 & 2 & 0.261 & 0.085 & 25.551 & 0.000 \\
\hline 1 & 1 & 든 & 1 & 3 & -0.019 & -0.200 & 25.586 & 0.000 \\
\hline$\square$ & 1 & $\square$ & 1 & 4 & -0.281 & -0.297 & 33.575 & 0.000 \\
\hline$\square$ & 1 & $\square$ & 1 & 5 & -0.450 & -0.278 & 54.267 & 0.000 \\
\hline 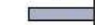 & 1 & $\square$ & 1 & 6 & -0.763 & -0.635 & 114.52 & 0.000 \\
\hline$\square$ & 1 & 10 & 1 & 7 & -0.442 & -0.101 & 134.93 & 0.000 \\
\hline$\square$ & 1 & 믐 & 1 & 8 & -0.293 & -0.169 & 144.01 & 0.000 \\
\hline 1 & 1 & 믐 & 1 & 9 & -0.024 & -0.162 & 144.07 & 0.000 \\
\hline 1 & $\ominus$ & 드 & 1 & 10 & 0.226 & -0.152 & 149.62 & 0.000 \\
\hline 1 & $\square$ & 1 & 1 & 11 & 0.451 & 0.001 & 171.97 & 0.000 \\
\hline 1 & & 1 & $\square$ & 12 & 0.813 & 0.477 & 245.27 & 0.000 \\
\hline
\end{tabular}

Figure 9

Autocorrelation and partial autocorrelation values of the lags of series - foreign tourists

Both models will be presented, from which the initial model consists of the first and $12^{\text {th }}$ lag of the series, whilst the second model contains the first, $12^{\text {th }}$ and $5^{\text {th }}$ lag. Table 5 below introduces the comparison of the models.

Table 5

Models for series of foreign tourists in the Republic of Macedonia 01:2010-08:2018

Dependent Variable: LOG_FOREIGN D

Method: ARMA Maximum Likelihood (OPG BHHH)

Date: 12/11/18 Time: 19:28

Sample: 2010M02 2018M08

Included observations: 103

Convergence achieved after 96 iterations

Coefficient covariance computed using outer product of gradients

\begin{tabular}{|c|c|c|c|c|c|c|c|c|c|}
\hline Variable & $\left|\begin{array}{c}\text { Coeffici } \\
\text { ent }\end{array}\right|$ & Std. Error $t$ & t-Stat & Prob. & Variable & $\mid \begin{array}{c}\text { Coefficie } \\
\mathrm{nt}\end{array}$ & \begin{tabular}{|l} 
Std. \\
Error
\end{tabular} & t-Stat & Prob. \\
\hline $\operatorname{AR}(12)$ & 0.9883 & 0.0095 & 103.51 & 0.00 & $\mathrm{AR}(12)$ & 0.946817 & 0.03131 & 30.2346 & 0.0000 \\
\hline $\mathrm{MA}(1)$ & -0.7032 & 0.0545 & -12.904 & 0.00 & MA(1) & -0.535643 & \begin{tabular}{|l|}
0.07428 \\
\end{tabular} & -7.2110 & 0.0000 \\
\hline MA(12) & -0.2391 & 0.0564 & -4.239 & 0.00 & $\operatorname{MA}(5)$ & -0.357282 & 0.08642 & -4.1341 & 0.0001 \\
\hline \begin{tabular}{|l|} 
SIGMASQ \\
\end{tabular} & 0.0072 & 0.0013 & 5.5099 & 0.00 & SIGMASQ & 0.007650 & 0.00189 & 4.02862 & 0.0001 \\
\hline R-squared & 0.88962 & \multicolumn{2}{|c|}{$\begin{array}{l}\text { Mean dependent } \\
\text { var }\end{array}$} & 0.01994 & R-squared & 0.894424 & \multicolumn{2}{|c|}{$\left.4\right|_{\text {var }} ^{\text {Mean dependent }}$} & 0.02150 \\
\hline \begin{tabular}{|l|} 
Adjusted \\
R-squared \\
\end{tabular} & 0.88628 & \multicolumn{2}{|c|}{8 S.D. dependent var } & 0.25665 & \begin{tabular}{|l|} 
Adjusted \\
R-squared \\
\end{tabular} & 0.890256 & \multicolumn{2}{|c|}{$\begin{array}{l}\text { S.D. dependent } \\
\text { var }\end{array}$} & 0.27088 \\
\hline $\begin{array}{l}\text { S.E. of } \\
\text { regression }\end{array}$ & 0.08654 & \multicolumn{2}{|c|}{$\begin{array}{l}\text { Akaike info } \\
\text { criterion }\end{array}$} & -1.626 & \begin{tabular}{|l|} 
S.E. of \\
regression \\
\end{tabular} & 0.089738 & \multicolumn{2}{|c|}{$\begin{array}{l}\text { Akaike info } \\
\text { criterion }\end{array}$} & -1.5973 \\
\hline \begin{tabular}{|l|} 
Sum sqr \\
residuals \\
\end{tabular} & 0.74155 & \multicolumn{2}{|c|}{ Schwarz criterion } & -1.52379 & $\begin{array}{l}\text { Sum sqr } \\
\text { residuals }\end{array}$ & 0.612021 & \multicolumn{2}{|c|}{1 Schwarz criterion } & -1.4782 \\
\hline \begin{tabular}{|l} 
Log \\
likelihood \\
\end{tabular} & 87.7450 & \multicolumn{2}{|c|}{$\begin{array}{l}\text { Hannan-Quinn } \\
\text { criter. }\end{array}$} & -1.58467 & \begin{tabular}{|l|} 
Log \\
likelihood \\
\end{tabular} & 67.89400 & \multicolumn{2}{|c|}{$\begin{array}{l}\text { Hannan-Quinn } \\
\text { criter. }\end{array}$} & -1.5495 \\
\hline DW stat & 1.79844 & & & & DW stat & 2.07777 & & & \\
\hline \multicolumn{5}{|c|}{ Model 1} & \multicolumn{5}{|c|}{ Model 2} \\
\hline
\end{tabular}

Dependent Variable: LOG_FOREIGN D

Method: ARMA Maximum Likelihood (OPG BHHH)

Date: 12/11/18 Time: 22:08

Sample: 2012M01 2018M08

Included observations: 80

Convergence achieved after 30 iterations

Coefficient covariance computed using outer product of gradients 
Several conclusions can be deducted from the results of the preparation of model 1 :

- Incorporated independent variables have low probability of rejection from the model, or high value of t-statistics

- The displayed model covers more than $88 \%$ of the variance of the series

- Durbin-Watson - DW statistics has a value close to 2 which can be an indicator for absence of serial correlation of residuals. However, further testing is necessary for assessing the hypothetical correlation of the residuals.

To conclude, the Correlogram stated in Figure 10 for model 1 clarifies that the fifth lag is outside the confidence interval. This prompted a search for another model appropriate for the series, including an examination of the series for a possible break.

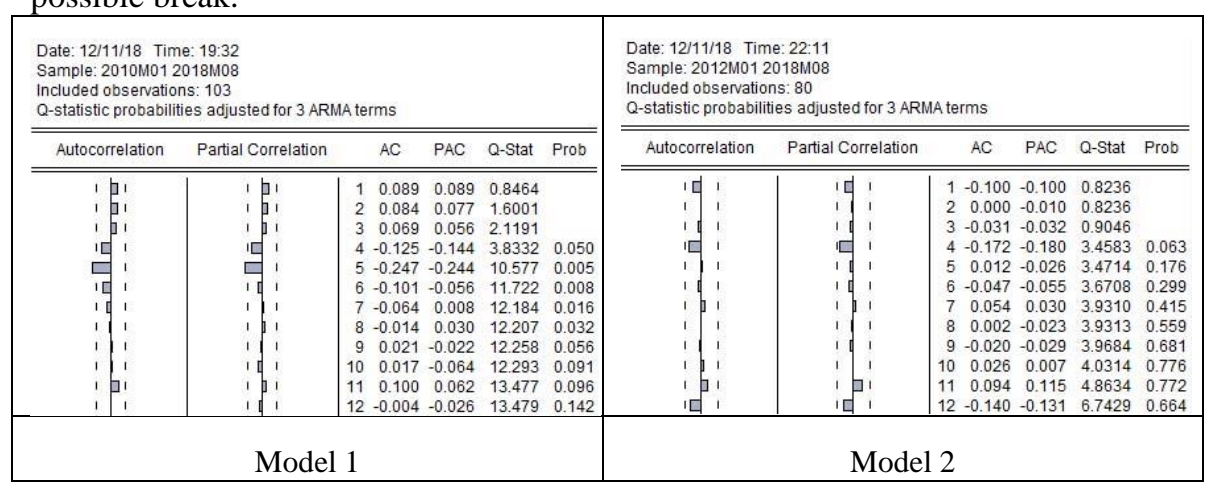

Figure 10

Correlogram on residuals for analyzed time series of arrived foreign tourists in Macedonia

The values from Table 6 and the graphical presentation in Figure 11 based on the Dickey-Fuller t-stat reveal that there is a structural break in the series of arrived tourists at the end of 2011. Thus, in order to have a stationary series without occurring structural breaks, a resampling of the series for the period 2012-2018 was conducted. The preceding data is enough to make a valid model (more than 50 samples) and this new series can be modeled as concluded from previous tests and results.

Table 6

Structural break at a time series of arrived foreign tourists

Null Hypothesis: LOG_FOREIGND has a unit root

Trend Specification: Intercept only

Break Specification: Intercept only

Break Type: Innovational outlier

Break Date: 2011M10 
Break Selection: Minimize Dickey-Fuller t-statistic

Lag Length: 11 (Automatic - based on Schwarz information criterion, maxlag=12)

\begin{tabular}{lccc}
\hline \hline & & t-Statistic & Prob.* \\
\hline \hline Augmented Dickey-Fuller test statistic & -5.781147 & $<0.01$ \\
& 1\% level & -4.949133 & \\
Test critical & $5 \%$ level & -4.443649 & \\
values: & 10\%level & -4.193627 & \\
& \hline \hline
\end{tabular}

Results on modeling for this series can be subtracted from Table 5, model 2. This model has the following characteristics:

- Incorporated independent variables have low probability of rejection from the model, or high value of t-statistics

- The represented model covers more than $89 \%$ of the variance of the series

- The Durbin-Watson statistics has a value close to 2 which can be an indicator for the absence of serial correlation of residuals, however, further testing of the residuals is required

A comparison of Akaike and Hannan Quinn information criterion indicates that model 2 has lower values for both criteria, which consequently suggests that this model is more applicable than model 1. As models have the same number of independent variables, this does not affect the results of criteria. Furthermore, the results of the Correlogram on the residuals of model 2 imply that residuals are uncorrelated, and subsequently, there are no values outside the confidence interval, thus model 2 is a valid model for this series.

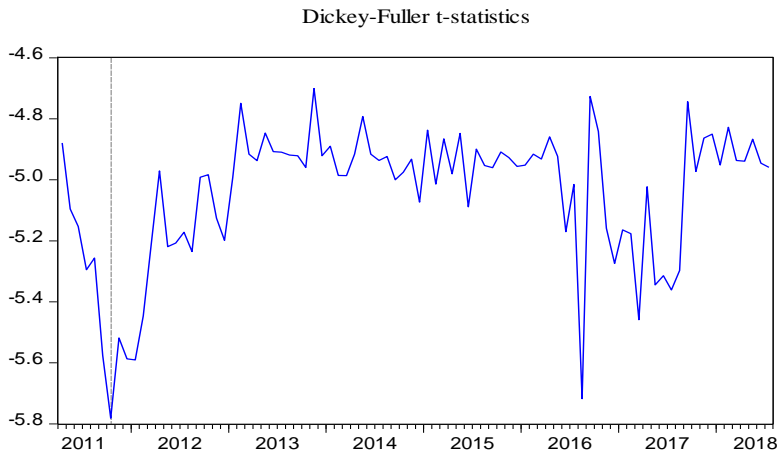

Figure 11

Structural break graph at the end of 2011 - series of foreign tourists 


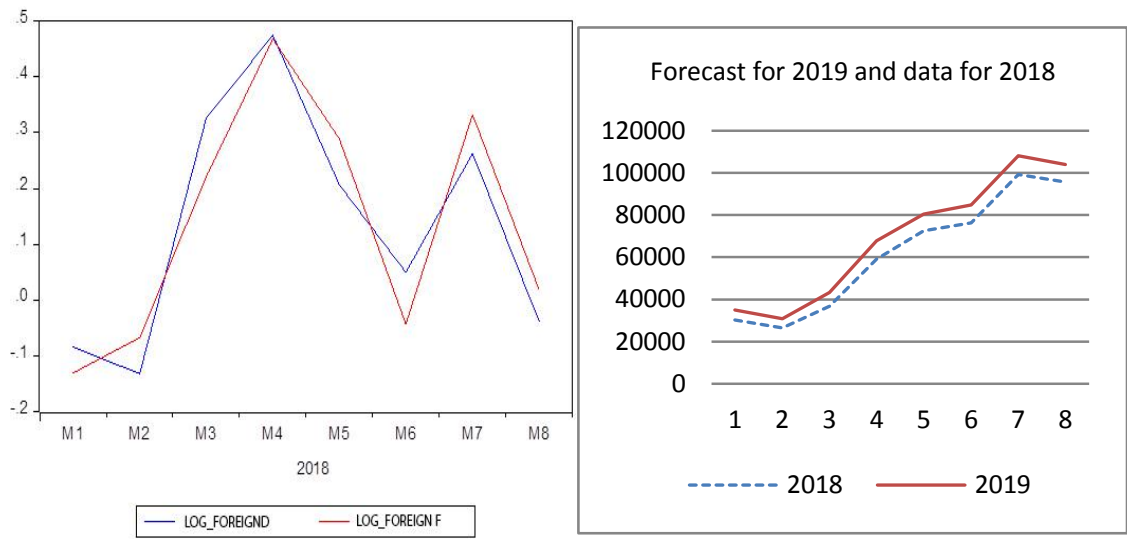

Figure 12

Original and predicted time series - arrived foreign tourists, Republic of Macedonia

Implementing the model that has proven to be superior, we can make a forecast for 2019. The results acquired from the use of the aforementioned model are portrayed in Figure 12. In addition, from the two graphs showcased in Figure 12, the first one is an in-sample forecast on-log and differenced series, while the second one is the forecast for 2019 vs 2018.

The following analysis and modeling on the series of arrived tourists in the Republic of Macedonia is about the first series of domestic tourists.

Before undertaking the analysis, the series should be tested for conceivable break point(s). The graphical presentation of the series in Figure 3 shows different behaviors of the series during the analyzed period. The completed unit root break test is documented in Figure 13.

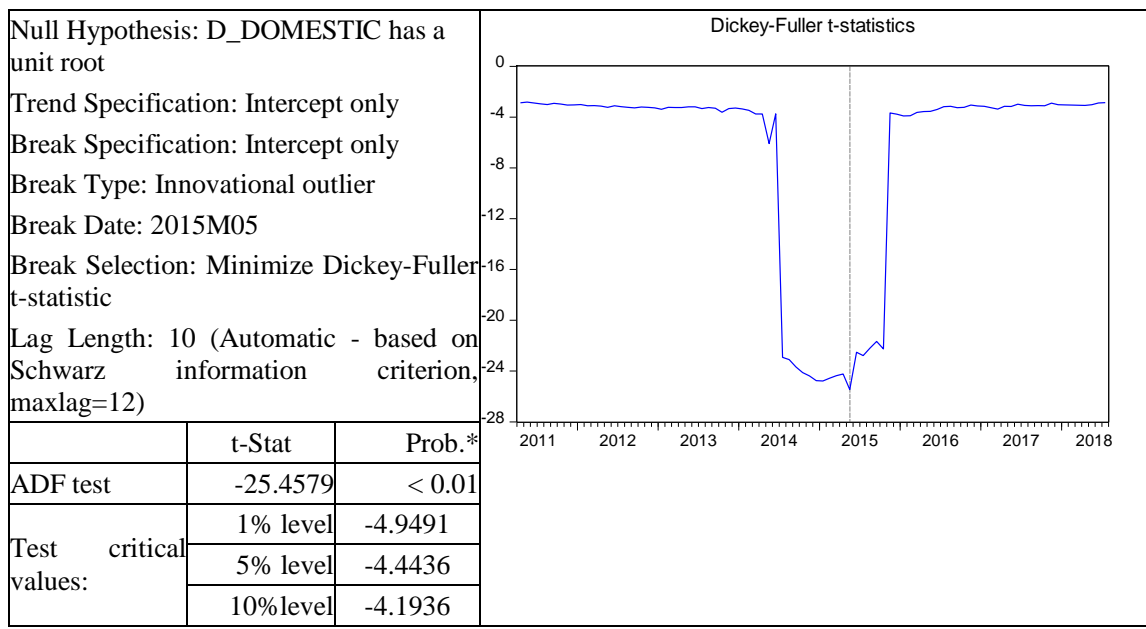

Figure 13

Unit root break test on the time series of arrived domestic tourists 
The results in Figure 13, suggest that there is a break point in the series detected in 2015. Resampling the series 01:2015-08:2015 reveals that the number of data in the new series is slightly higher than the minimum series of 30 samples. The resampling and differencing of the series in order to get a stationary one was performed, from which results can be noted from Table 7 .

Table 7

Unit root test results for the series of domestic tourists in the Republic of Serbia

Null Hypothesis: D_DOMESTIC has a unit root, Exogenous: Constant

Lag Length: 8 (Automatic - based on SIC, maxlag=9)

\begin{tabular}{lrcc}
\hline \hline & & & \\
\hline & & t-Statistic & Prob.* \\
\hline Augmented Dickey-Fuller test statistic & -6.220455 & 0.0000 \\
\hline Test critical values: & $1 \%$ level & -3.588509 & \\
& $5 \%$ level & -2.929734 & \\
& $10 \%$ level & -2.603064 & \\
\hline \hline
\end{tabular}

As can be seen by the results from Table 7 , the differenced time series is a stationary one. This concludes that the probability of rejection of null hypothesis is quite low. At this point, a Correlogram can be created in order to detect the crucial lags in the series. It has an evident trend and heteroscedasticity, which has prompted both a logarithmic transformation, and first lag differencing on the series. The Correlogram for the transformed and differenced series is presented in Figure 14.

The Correlogram in Figure 14, indicates that the $12^{\text {th }}$ lag is significant, which suggests that there is a serial correlation, meaning that the first and $12^{\text {th }}$ lag should be involved in the model. The proposed model, along with its associate statistics is showcased in Table 8.

\begin{tabular}{|c|c|c|c|c|c|c|c|}
\hline Autocorrelation & Partial Cor & irrelation & & $A C$ & PAC & Q-Stat & Prob \\
\hline 1ם । & । & 1 & & -0.262 & -0.262 & 3.2256 & 0.072 \\
\hline । 曰 & 10 & ב 1 & 2 & 0.177 & 0.117 & 4.7415 & 0.093 \\
\hline $1 \sqrt{1}$ & & 1 & & -0.042 & 0.032 & 4.8278 & 0.185 \\
\hline 101 & 10 & 1 & & -0.058 & -0.089 & 4.9976 & 0.288 \\
\hline 101 & 1 든 & 1 & & -0.118 & -0.166 & 5.7237 & 0.334 \\
\hline$\square \quad 1$ & $\square$ & 1 & & -0.295 & -0.379 & 10.363 & 0.110 \\
\hline 1 ] 1 & $\square$ & 1 & & -0.087 & -0.292 & 10.776 & 0.149 \\
\hline 101 & 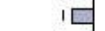 & 1 & & -0.118 & -0.222 & 11.559 & 0.172 \\
\hline 171 & 1 & 1 & 9 & 0.023 & -0.124 & 11.589 & 0.237 \\
\hline 1 口 & 10 & 1 & 10 & 0.129 & 0.050 & 12.582 & 0.248 \\
\hline 1다 । & $\square$ & 1 & 11 & -0.186 & -0.398 & 14.701 & 0.197 \\
\hline $1 \rightleftharpoons$ & $1 E$ & $\square$ & 12 & 0.659 & 0.396 & 42.206 & 0.000 \\
\hline
\end{tabular}

Figure 14

Correlogram for the transformed and differenced time series of arrived domestic tourists 
Table 8

Models for series of domestic tourists in the Republic of Serbia

Dependent Variable:

DLOG_DOMESTIC

Method: ARMA Maximum Likelihood

Date: $12 / 15 / 18$ Time: $10: 25$

Sample: 2015M01 2018M08

Included observations: 44

Convergence achieved after 18 iterations

Coefficient covariance computed using outer product of gradients

\begin{tabular}{|l|l|l|l|l|}
\hline Variable & Coefficient & $\begin{array}{c}\text { Std. } \\
\text { Error }\end{array}$ & $\begin{array}{c}\text { t- } \\
\text { Statistic }\end{array}$ & Prob. \\
\hline AR(12) & 0.98130 & 0.00868 & 113.05 & 0.000 \\
\hline MA(1) & -0.85245 & 0.10141 & -8.405 & 0.000 \\
\hline SIGMASQ & 0.00043 & $6.27 E-05$ & 6.9697 & 0.000 \\
\hline R-sqr & 0.94942 & $\begin{array}{l}\text { Mean dependent } \\
\text { var }\end{array}$ & 0.008452 \\
\hline Adj R-sqr & 0.94696 & $\begin{array}{l}\text { S.D. dependent } \\
\text { var }\end{array}$ & 0.094046 \\
\hline $\begin{array}{l}\text { S.E. of } \\
\text { regression }\end{array}$ & 0.02165 & $\begin{array}{l}\text { Akaike } \\
\text { criterion }\end{array}$ & -3.83978 \\
\hline $\begin{array}{l}\text { Sum sqr } \\
\text { residuals }\end{array}$ & 0.01923 & $\begin{array}{l}\text { Schwarz } \\
\text { criterion }\end{array}$ & -3.71813 \\
\hline $\begin{array}{l}\text { Log } \\
\text { likelihood }\end{array}$ & 87.47527 & $\begin{array}{l}\text { Hannan-Quinn } \\
\text { criter. }\end{array}$ & -3.79467 \\
\hline DW stat & 1.68946 & & \\
\hline
\end{tabular}

Dependent Variable: DLOG_DOMESTIC

Method: ARMA Maximum Likelihood

Date: $12 / 15 / 18$ Time: $11: 34$

Sample: 2015M01 2018M08

Included observations: 44

Convergence achieved after 40 iterations

Coefficient covariance computed using outer product of gradients

\begin{tabular}{|l|c|c|c|c|}
\hline Variable & Coefficient & $\begin{array}{c}\text { Std. } \\
\text { Error }\end{array}$ & $\begin{array}{c}\mathrm{t}- \\
\text { Statistic }\end{array}$ & Prob. \\
\hline AR(12) & 0.992810 & 0.003790 & 261.9713 & 0.000 \\
\hline SAR(12) & -0.45479 & 0.113553 & -4.00511 & 0.000 \\
\hline MA(1) & -0.85910 & 0.124190 & -6.91767 & 0.000 \\
\hline SIGMASQ & 0.00035 & $5.84 \mathrm{E}-05$ & 6.007008 & 0.000 \\
\hline R-sqr & 0.959437 & $\begin{array}{l}\text { Mean dependent } \\
\text { var }\end{array}$ & 0.00845 \\
\hline Adj R-sqr & 0.956395 & $\begin{array}{l}\text { S.D. dependent } \\
\text { var }\end{array}$ & 0.09404 \\
\hline $\begin{array}{l}\text { S.E. of } \\
\text { regression }\end{array}$ & 0.0196 & $\begin{array}{l}\text { Akaike info } \\
\text { criterion }\end{array}$ & -3.8925 \\
\hline $\begin{array}{l}\text { Sum sqr } \\
\text { residuals }\end{array}$ & 0.0154 & Schwarz criterion & -3.7303 \\
\hline $\begin{array}{l}\text { Log } \\
\text { likelihood }\end{array}$ & 89.636 & $\begin{array}{l}\text { Hannan-Quinn } \\
\text { criter. }\end{array}$ & -3.8324 \\
\hline DW stat & 1.6682 & & \\
\hline
\end{tabular}

The results from Table 8 reveal that:

- Included independent variables have low probability of rejection from the model, or high value of $t$-statistics

- $\quad$ The stated model covers more than $94 \%$ of the variance of the series

- DW statistics has a value close to 2 which can be an indicator of absence of serial correlation of residuals, however, the residuals should be tested.

The Correlogram in Figure 15 for model 1 indicates that the $12^{\text {th }}$ lag is outside of the confidence interval. An attempt was made to contain a seasonal component in order for a model with uncorrelated residuals to be created. 


\begin{tabular}{|c|c|c|c|c|c|c|c|c|c|c|c|c|c|}
\hline \multicolumn{7}{|c|}{$\begin{array}{l}\text { Date: } 12 / 15 / 18 \text { Time: } 11: 41 \\
\text { Sample: } 2015 \text { M01 2018M08 } \\
\text { Included observations: } 44 \\
\text { Q-statistic probabilities adjusted for } 2 \text { ARMA terms }\end{array}$} & \multicolumn{7}{|c|}{$\begin{array}{l}\text { Date: } 12 / 15 / 18 \text { Time: } 11: 50 \\
\text { Sample: } 2015 \text { M0 } 12018 M 08 \\
\text { Included observations: } 44 \\
\text { Q-statistic probabilities adjusted for } 3 \text { ARMA terms }\end{array}$} \\
\hline Autocorrelation & Partial Correlation & & $A C$ & PAC & Q-Stat & Prob & Autocorrelation & Partial Correlation & & AC & PAC & Q-Stat & Prob \\
\hline 口， & 口～ & 1 & 0.148 & 0.148 & 1.0313 & & 口！ & 口！ & 1 & 0.163 & 0.163 & 1.2506 & \\
\hline 151 & 131 & 2 & 0.071 & 0.050 & 1.2762 & & 181 & $1 \sqrt{1}$ & 2 & 0.088 & 0.064 & 1.6273 & \\
\hline 101 & 101 & 3 & -0.066 & -0.086 & 1.4911 & 0.222 & 151 & 101 & 3 & -0.083 & -0.110 & 1.9656 & \\
\hline 181 & 1 1 & 4 & 0.089 & 0.110 & 1.8938 & 0.388 & 1 & 1 & 4 & 0.003 & 0.028 & 1.9660 & 0.161 \\
\hline 101 & 101 & 5 & -0.080 & -0.104 & 2.2296 & 0.526 & 101 & 1 & 5 & -0.056 & -0.047 & 2.1303 & 0.345 \\
\hline 11 & 11 & 6 & 0.018 & 0.029 & 2.2468 & 0.690 & 101 & 1 & 6 & 0.044 & 0.050 & 2.2323 & 0.526 \\
\hline 181 & 181 & 7 & 0.087 & 0.114 & 2.6630 & 0.752 & 171 & 171 & 7 & 0.077 & 0.077 & 2.5558 & 0.635 \\
\hline 101 & 며 & 8 & -0.131 & -0.206 & 3.6324 & 0.726 & 101 & 101 & 8 & -0.109 & -0.161 & 3.2275 & 0.665 \\
\hline ，尸! & ： & 9 & 0.179 & 0.278 & 5.4915 & 0.600 & 1 ' & ' & 9 & 0.164 & 0.223 & 4.7833 & 0.572 \\
\hline ） & 181 & 10 & 0.127 & 0.072 & 6.4462 & 0.597 & 111 & 1 & 10 & 0.031 & -0.008 & 4.8403 & 0.679 \\
\hline 11 & 마 & 11 & -0.034 & -0.192 & 6.5171 & 0.687 & 151 & 1 & 11 & -0.080 & -0.162 & 5.2325 & 0.732 \\
\hline 미 & 미 & 12 & -0.307 & -0.193 & 12.466 & 0.255 & 1 & 101 & 12 & 0.008 & 0.128 & 5.2363 & 0.813 \\
\hline
\end{tabular}

Figure 15

Correlation of residuals for both models: series of arrived domestic tourists - Serbia

The residuals of the second model are not correlated, which indicates that it is to be rendered as valid for representing this time series. Suitably, the results of modeling given in Table 8 specify that Akaike and Hannan Quinn criteria have lower values for the first model, due to the number of independent variables. Then again, model 1 cannot be selected, as it is not relevant for this time series. What follows is a forecast calculated by the model. Figure 16 is presenting an in sample forecast.
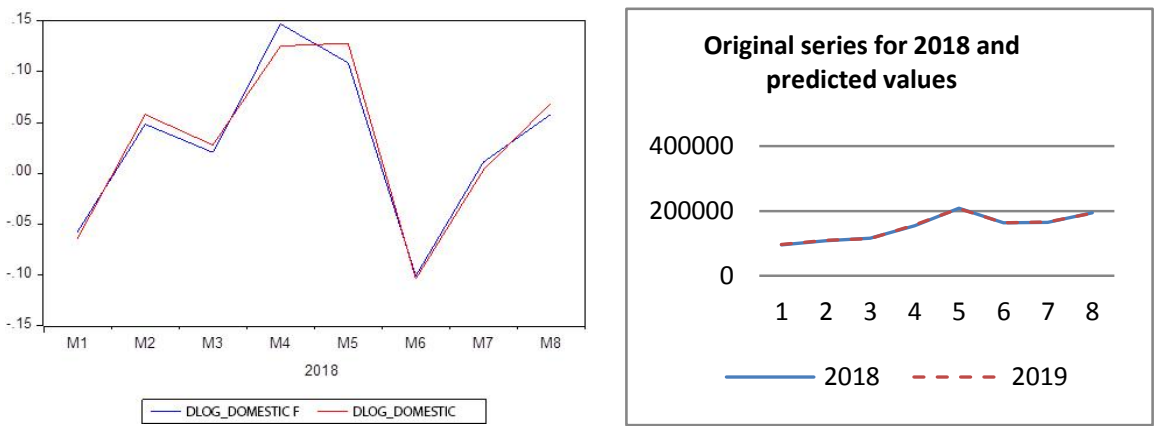

Figure 16

In sample and out of sample forecast for time series of arrived domestic tourists - Serbia

The last time series analyzed in this paper is the series of arrived foreign tourists in the Republic of Serbia, as can be deducted from Figure 3. As concluded earlier, this series should be tested for impending structural breaks, as there are evident differences in the behavior of the series over a longer period. This time series has an accentuated trend and heteroscedasticity. As means to eliminate the heteroscedasticity and trend a transformation on the series was performed, which contained a differentiation and log transformation. Likewise, whether the time series is stationary was tested with a unit root test. 
The results specified in Table 9 indicate that the value of t-statistics is lower than the critical values, and the probability to reject null hypothesis of stationary series is very low. Henceforth, the resulting time series is stationary.

Table 9

Results of unit root test for the series of arrived foreign tourists - Republic of Serbia

Null Hypothesis: LOGD_FOREIGN has a unit root, Exogenous: Constant

Lag Length: 10 (Automatic - based on SIC, maxlag=10)

\begin{tabular}{llll}
\hline \hline & & & \\
\hline & \multicolumn{1}{l}{ t-Statistic } & Prob. $^{*}$ \\
\hline Tugmented Dickey-Fuller test statistic & -14.92968 & 0.0001 \\
\hline Test critical values: & $1 \%$ level & -3.528515 & \\
& $5 \%$ level & -2.904198 & \\
& $10 \%$ level & -2.589562 & \\
\hline \hline
\end{tabular}

As depicted in Figure 17, a test was performed to examine the series for potential structural breaks.

Null Hypothesis: LOGD_FOREIGN has a unit root

Trend Specification: Intercept only

Break Specification: Intercept only

Break Type: Innovational outlier

Break Date: 2017M02

Break Selection: Minimize DF t-statistic

Lag Length: 10 (Automatic - based on Schwarz information criterion, maxlag $=10$ )

\begin{tabular}{ccc}
\hline & t-Statistic & Prob. $^{*}$ \\
\hline ADF test & -15.823 & $<0.01$ \\
Test $1 \%$ level & -4.9491 & \\
critical $5 \%$ level & -4.4436 & \\
values: $10 \%$ level & -4.1936 & \\
\hline
\end{tabular}

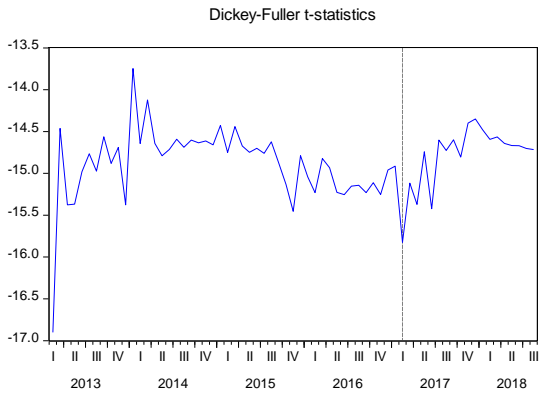

Figure 17

Structural break unit root test. Time series of foreign tourists in the Republic of Serbia

Additionally, the results represented in Figure 17 show that this series has a structural break at the beginning of 2017, meaning that, there is not enough sample data to serve as basis for a valid model. Models for identification of time series with existing structural breaks can be found in literature, such as models based on Artificial Neural Networks, yet their structure is very complex. In these models, the number of variables is much higher than the variables from ARIMA, and the forecasting is not as accurate as those created with linear models [3] [4].

Some authors [6] propose a combination of linear and non-linear models to get the best results, even though these models are more complex, and in most cases are hardly superior to linear models. They test in [9] [6] [19], the models going by the values of the residuals and the error between the original series and model with calculated MAPE and MAE errors. 
In this paper, the accuracy of the models is between $88 \%$ and $97 \%$, although that is not the main issue, but only one aspect of designing a valid model. The reasons for changes of the behavior of the series, as well as the period of the changes need to be identified. That is why the design of the model for this series will not be continued.

\section{Analysis of Government Decisions Concerning Tourism}

For the analyzed countries in the Balkans, the government decisions for the improvement of tourism have been considered as well. Both of these countries have subsidies for tourism. Granted, both countries have different approaches toward the type of subsidies, the choices for each of them were tested. Subsequently, the analysis of the implemented strategies in the Republic of Macedonia was conducted first, in which the period 2011-2018 was considered in order to make an appropriate analysis.

The unit root test for structural break(s) was selected as a valid methodology on testing decisions, where structural break(s) in time series is an abrupt change at a point in time. This change could involve a change in mean or the other parameters of the process that produce time series, such as variance or trend.

The most important assumption under the unit root [11] is that the random shocks have permanent effects on the long-run level of series. Correspondingly, these findings were challenged by [14], who argues that in the presence of a structural break, the standard ADF tests are biased towards the non-rejection of the null hypothesis [10]. Evidence of such an example can be found in the analyzed series of arrived foreign tourists in the Republic of Serbia, within this paper. According to the ADF test, the series is stationary after the first difference, but that shock is not on the long-run level of the series as can be concluded after the unit root break test.

Contrarily, Perron proposes a modified Dickey Fuller - (DF) unit root test with included dummy variables, to test the known or exogenous structural break. There are three types of possible structural breaks: First, changes in level of the series, second, changing of the trend (slope) in the series and third, a combination of the first and second break. Those three types are summed in the following equations:

$$
\begin{aligned}
& x_{t}=\alpha_{0}+\alpha_{1} D U_{t}+d(D T B)_{t}+\beta t+\rho x_{t-1}+\sum_{i=1}^{p} \phi_{i} \Delta x_{t-1}+\varepsilon_{t} \\
& x_{t}=\alpha_{0}+\gamma D T_{t}+\beta t+\rho x_{t-1}+\sum_{i=1}^{p} \phi_{i} \Delta x_{t-1}+\varepsilon_{t} \\
& x_{t}=\alpha_{0}+\alpha_{1} D U_{t}+d(D T B)_{t}+\gamma D T_{t}+\beta t+\rho x_{t-1}+\sum_{i=1}^{p} \phi_{i} \Delta x_{t-1}+\varepsilon_{t}
\end{aligned}
$$


Where $D U_{t}$ is the intercept dummy which tests the change in the level; $D T_{t}$ is the slope dummy which tests the slope in some interval of the series and TB is a date of a structural break. All models have a unit root with a break under the null hypothesis [10].

The first analyzed time series is the time series of arrived Dutch tourists in the Republic of Macedonia in 2011. This is the first year after the decision of the government to give subsidies in order for tour-operators to bring tourists from the Benelux region. Figure 11 shows that there is a structural break in the series of arrived foreign tourists. Therefore, the series of arrived foreign tourists from the Netherlands were tested next to show whether there is a structural break after the applied strategies.

Null Hypothesis: D(DUTCH) has a unit root

Trend Specification: Intercept only

Break Specification: Intercept only

Break Type: Innovational outlier

Break Date: 2011M07

Break Selection: Minimize DF t-statistic

Lag Length: 11 (Automatic - based on

Schwarz information criterion, maxlag=12)

\begin{tabular}{cccc}
\hline \hline & t-Statistic & Prob.* \\
\hline \hline ADF test & -4.6350 & 0.029 \\
\hline Test & $1 \%$ level & -4.9491 & \\
critical & $5 \%$ level & -4.4436 & \\
values: & $10 \%$ level & -4.1936 & \\
\hline \hline
\end{tabular}
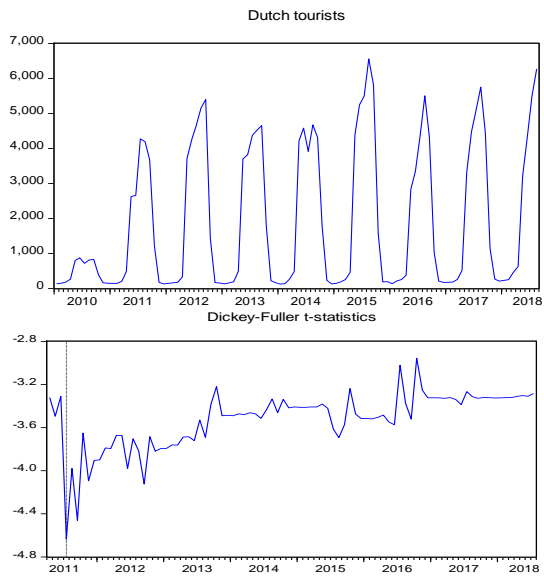

Figure 18

Time series and unit root structural break test for series of arrived tourists from Netherlands

Figure 18 reveals the time series of arrived Dutch tourists in the Republic of Macedonia and the corresponding structural break test for the series. Consequently, the results of the presentation and unit root structural break test indicate that:

- There is a difference in the level of arrived Dutch tourists in and after 2010

- The series is a seasonal, although a different behavior is present in different years, due to the different measures taken by the government, this series will be tested for another potential break

- From the results received from the break test we can conclude that there is a break in 2011, as expected based on different levels in the series

After 2010 a specific trend is not present and additionally there is a variation of the values around the mean value of the series 
Another time series of arrived tourists from Scandinavian countries will be tested as well. A time series of arrived tourists from Sweden was taken as an example. In the Official Gazette of the Republic of Macedonia, No 53 published on 11 of April 2013, the government of the Republic of Macedonia has announced subsidies for tourists from Sweden amounting to 25 euros per tourist. Figure 19 presents the time series of arrived tourists from Sweden, including a unit root break test for this series. The graph of the series indicates that:

- This time series has a trend and an accentuated heteroscedasticity. What is more, the increase in the number of foreign tourists arrived in 2017 compared to 2010 is $363 \%$

- Different behavior of the series in different years is evidenced, however, a proper test should be conducted such as a unit root test for a structural break

- There is no significant change in the level of the series in 2013, or 2014 as noted in the series of arrived tourists from the Netherlands.

The results given in the table of the unit root break test reveal that there is a structural break in the series in 2017. Contrarily, this structural break cannot be connected with the decision of the government in 2013. This leads to a conclusion that this decision did not bring the expected results measured by the increment in the number of arrived tourists from Sweden in the Republic of Macedonia. Moreover, the positive trend in the series can also be a result of the number of established direct air lines from Sweden to the Republic of Macedonia. ${ }^{2}$ An added difference between the decision made for tourists from Benelux and one for tourists from Scandinavian countries is that subsidies for Scandinavian tourists is 25 euros per tourist, despite the amount of 65 euros for the arrived tourists from Benelux.

Nonetheless, subsidies in the Republic of Serbia have a different character and purpose in relation to subsidies in the Republic of Macedonia.

In Serbia, judging by the annual competitions for tourism subsidies envisaged under the established Strategy for development of tourism in the Republic of Serbia for the time between 2016 and $2025^{3}$, subsidies may be received by domestic legal entities for the following purposes: promotion of tourism products, progress of satellite account statistics, education and training in tourism, arrangement of space, creation of planning documentation, arrangement of public areas, etc.

2 In 2013 airline company Wizzair established direct lines from Skopje to Stockholm and Goteborg

http://mtt.gov.rs/download/3/strategija.pdf 


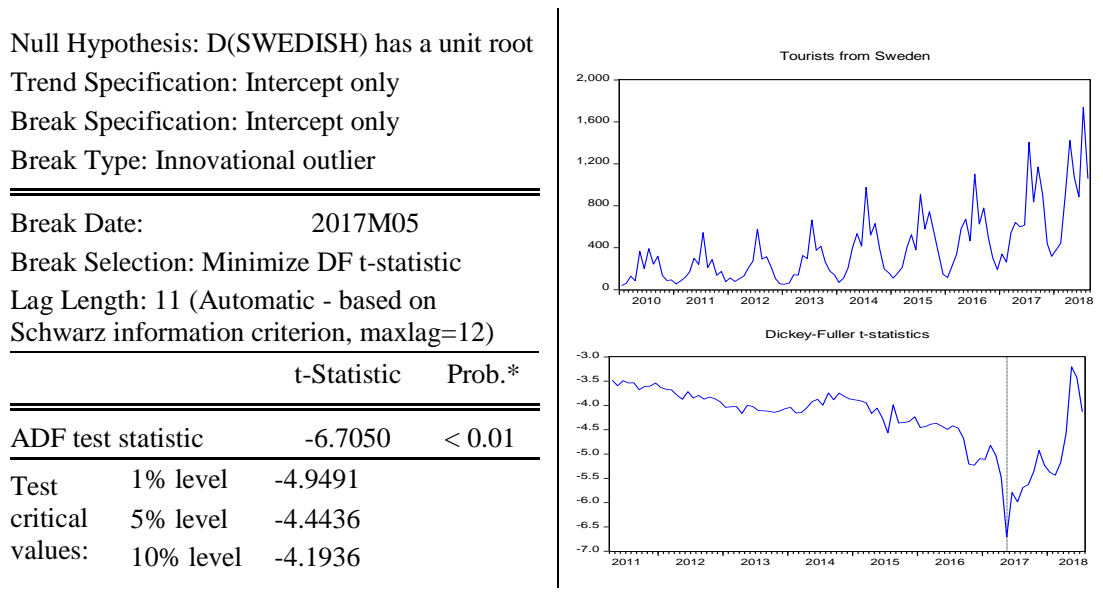

Figure 19

Time series and unit root structural break test for time series of arrived tourists from Sweden

This diverts the attention to the previous analysis of the series of arrived tourists in the Republic of Serbia. Subsequently, for foreign tourists, the structural break is at the beginning of 2017, which may indicate a result of the measures provided for the Tourism Development Strategy 2016-2025.

\section{Conclusions}

From our conducted analysis on time series of the number of visiting tourists in two neighboring countries in the Balkans, we can conclude, that in spite of the similarities in the characteristics of the series, the generated models can differ. Even though all of them have seasonal components and a significant serial correlation, each model has unique characteristics. What is more, all models are tested for validity, adding to the attempt at creating a concurrent model, which is chosen as per the results of the accompanied information criteria. Moreover, one of the essential parts in the analysis is the presence of any structural break(s) in the time series, which can influence choices, or events that have happened during a given period of the analysis. Likewise, they can serve as a basis for testing decisions of the Government or other Governmental body, that are responsible for any strategies and assessments designed to improve Tourism in their country. As deduced from the analysis, some implemented strategies have an impact on the advancement of Tourism, whereas some of them do not. However, the main goals in the development of Tourism, is the growth of the number of arriving foreign tourists and to ensure that the target has been reached for the concerned country.

\section{References}

[1] Andreeski, Cvetko, and Pandian Vasant. "Comparative analysis on time series with included structural break." Proceedings of the Second Global 
Conference on Power Control and Optimization. Bali: American Institute of Physics, 2009, 217-224

[2] Baldigara, Tea, and Maja Mamula. "Modelling International Tourism Demand." Tourism and Hospitality Management, Vol. 21, No. 1, 2015: 1931

[3] Benkachca, S, J Behra, and H El Hassani. "Causal Method and Time Series Forecasting model based on Artificial Neural Network." International Journal of computer Applications (0975-8887), August 2013: 37-42

[4] Benkachcha, S, S Benhra, and H El Hassani. "Seasonal Time Series Forecasting Models based on Artificial Neural Network." International Journal of Computer Applications (0975-8887) Vol. 166, 2015: 9-14

[5] Brockwell, Peter J, and Richard A Davis. Introduction to Time Series and Forecasting, Second Edition. New York: Springer, 2002

[6] Chen, K. Y. "Combining linear and nonlinear model in forecasting tourism demand." In Expert Systems with Applications, 10368-10376, Vol. 38, 2011

[7] Ette, Etuk Harrison. "A Seasonal Arima Model for Nigerian Gross Domestic Product." Developing Country Studies, Vol. 2, No. 3, 2012: 50-62

[8] Fazekas, Mária. "Time Series Models on Medical Research." Periodica Polytechnica Ser. El. Eng. Vol. 49, No. 3-4, 2005: 175-181

[9] Fong-Lin, Chu. "Forecasting tourism demand: a cubic polynomial approach." Tourism Management 25, 2004: 209-218

[10] Glynn, J, N Perera, and R Verma. "Unit root tests and structural breaks: a survey with applications." Journal of Quantitative Methods for Economics and Business Administration, 3(1), 2007: 63-79

[11] Nelson, C R, and C I Plosser. "Trends and random walks In Macroeconomic Time Series." Journal of Monterey Economics, 10, 1982: 139-162

[12] O'Hare, Colin, and Youwei Li. "Identifying Structural Breaks in Stochastic Mortality Models." SSRN electronic Journal, 2015

[13] Oscar, Claveria, Monte Enric, and Torra Salvador. Tourism demand forecasting with different neural networks models. Barcelona: Research Institute of Applied Economics, 2013

[14] Perron, P. "The great crash, the oil price shock, and the unit root hypothesis." Econometrica 57, 1989: 1361-1401

[15] Petrevska, Biljana;. "Predicting tourism demand by A.R.I.M.A. models." Economic Research, doi 10.1080/1331677X.2017.1314822, 2015: 939-950 
[16] Ruey-Chyn, Tsaur, and Kuo Ting-Chun. "Tourism demand forecasting using a novel high precision fuzzy time series model." International Journal of Innovative Computing, Information and Control, 2014: 695-701

[17] Shengwei, Wang, Feng Juan, and Liu Gang. "Application of seasonal time series model in the precipitation forecast." Mathematical and Computer Modelling, Volume 58, Issues 3-4, 2013: 677-683

[18] Shitan, Mahedran, Pauline Mah Jin Wee, Lim Ying Chin, and Lim Ying Siew. "Arima and Integrated Arfima Models for Forecasting Annual Demersal and Pelagic Marine Fish Production in Malaysia." Malaysian Journal of Mathematical Sciences 2(2), 2008: 41-54

[19] Teixeira, J p, and P O Fernandes. "Teixeira, J. P., \& Fernandes, P. O. (2014). Tourism time series forecast with artificial neural networks. " Tékhne, 12(1-2), 26-36, doi:10.1016/j.tekhne., 2014: 26-36

[20] Victor Wong, Anand Tularam and Hamid Shobeir Nejad. "Modeling Tourist Arrivals Using Time Series Analysis: Evidence From Australia. "Journal of Mathematics and Statistics 8 (3), 2012: 348-360 